\title{
Tumour-Not So Sweet, Tumour-Induced Hypoglycemia: A Rare Case of Refractory Hypoglycemia in a Toddler
}

\author{
Jayati Joshipura ${ }^{a}$ Vani H.N. ${ }^{b}$ Nabanita Kora ${ }^{a}$ \\ ${ }^{a}$ Department of Pediatric and Adolescent Endocrinology, Indira Gandhi Institute of Child Health, Bengaluru, India; \\ ${ }^{b}$ Department of Pediatrics, Indira Gandhi Institute of Child Health, Bengaluru, India
}

\section{Keywords}

Hypoglycaemia Sarcoma Pediatric endocrinology

\begin{abstract}
Tumour-induced hypoglycaemia is a rare complication/condition mainly seen in adults. It is caused due to increased production of insulin or insulin-like growth factor (IGF) 2 tumour cells. We present a 3-year-old paediatric patient with non-islet cell tumour induced hypoglycaemia (NICTH) secondary to rhabdomyosarcoma. She presented with abdominal mass and refractory hypoglycaemia, requiring high glucose infusion and steroids. Critical sample analysis during hypoglycaemia showed suppression of insulin, IGF-1, C-peptide, growth hormone, and ketones, with a high cortisol level. CT scan of abdomen and pelvis showed a huge retroperitoneal mass, later diagnosed as rhabdomyosarcoma. In a resource-limited setting, where IGF-2 is not possible, low serum insulin and IGF-1 levels during hypoglycaemia aids in diagnosis of NICTH. This is one of the first few reported paediatric cases with NICTH from India, and we believe that reporting this case would add more information to the existing literature. Thus, NICTH should be suspected in all malignancies presenting with intractable hypoglycaemia irrespective of their age.

(c) 2021 The Author(s).

Published by S. Karger AG, Basel
\end{abstract}

\section{Introduction}

Non-islet cell tumour hypoglycaemia (NICTH) is a rare paraneoplastic syndrome which is associated with various kinds of tumours, mainly with intra-abdominal tumours of mesenchymal origin $[1,2]$. It is most commonly seen in adults and very rarely in children. The exact incidence of the disease is unknown; however, it is approximately 1 per million people years [3]. This is one of the first few reported paediatric cases with NICTH from India, and we believe that reporting this case would add more information to the existing literature.

\section{Case Presentation}

We present a case from India, a 3-year-old female patient admitted with complaints of progressive abdominal distension and lethargy. She was born through spontaneous vaginal delivery at term with no history of neonatal hypoglycaemia. Progressive abdominal distension and pedal oedema were noticed 2 weeks prior to admission. There was no history of fever, vomiting, convulsion, jaundice, or bleeding from any site.

On examination, the child was lethargic and marasmic with severe pallor. Abdomen was massively distended with dilated veins and an ill-defined mass was palpable in right hypochondrial region extending up-to right iliac region (shown in Fig. 1). Her blood sugar on admission was $45 \mathrm{mg} / \mathrm{dL}$. During hospital admission, she karger@karger.com www.karger.com/dde

Karger $\stackrel{\text { ' }}{5}$ BOPEN ACCESS
(C) 2021 The Author(s).

Published by S. Karger AG, Basel

This is an Open Access article licensed under the Creative Commons Attribution-NonCommercial-4.0 International License (CC BY-NC) (http://www.karger.com/Services/OpenAccessLicense), applicable to the online version of the article only. Usage and distribution for commercial purposes requires written permission.
Correspondence to:

Jayati Joshipura, jsjoshipura@gmail.com 


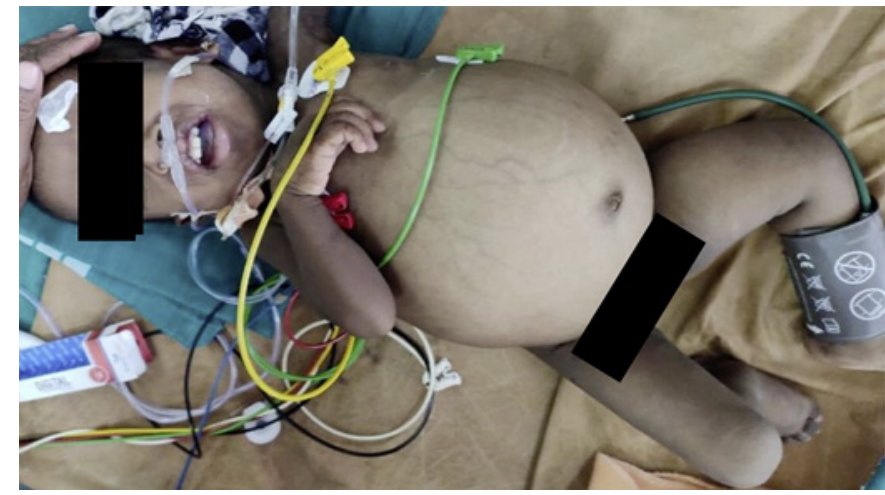

Fig. 1. Patient with gross abdominal distension.

Table 1. Results of critical samples

\begin{tabular}{lll}
\hline Lab & Serum level & Normal range \\
\hline Glucose & 45 & $70-100 \mathrm{mg} / \mathrm{dL}$ \\
Insulin & $<0.2$ & $<2 \mu \mathrm{lU} / \mathrm{mL}$ \\
C-peptide & 0.2 & $0.5-2.7 \mathrm{ng} / \mathrm{mL}$ \\
Beta-hydroxyl butyrate & 0.08 & $0.04-0.18 \mathrm{mmol} / \mathrm{L}$ \\
Cortisol & 18 & $5-10 \mu \mathrm{g} / \mathrm{dL}$ \\
GH & 1 & $>5 \mathrm{ng} / \mathrm{mL}$ \\
IGF-1 & 5 & $22-229 \mathrm{ng} / \mathrm{mL}$ \\
\hline
\end{tabular}

IGF, insulin-like growth factor; GH, growth hormone.

required glucose infusion rates of $15 \mathrm{mg} / \mathrm{kg} / \mathrm{min}$ with glucose-containing fluids and required hydrocortisone to maintain euglycaemia. Critical sample analysis during hypoglycaemia showed suppression of C-peptide, insulin, insulin-like growth factor (IGF)-1, growth hormone $(\mathrm{GH})$, and ketones, with a high cortisol level (shown in Table 1). IGF-2 levels could not be done due to nonavailability of test. Ultrasound abdomen and pelvis showed large necrotic mass lesion, extending from lower surface of the liver till the upper surface of urinary bladder. CECT abdomen and pelvis showed a heterogeneous retro-peritoneal mass $15 \times 15 \times 11 \mathrm{~cm}$. Ultrasound-guided biopsy was done, which confirmed diagnosis of rhabdomyosarcoma. She was referred to a paediatric oncologist and advised chemotherapy followed by surgical resection; however, the parents refused any further treatment.

\section{Discussion}

NICTH is a rare syndrome, secondary to a variety of benign and malignant tumours. It commonly presents in the adults with average period of symptoms from weeks to months before diagnosis. It was first reported by Daughaday et al. [4]. The tumours could be of mesenchymal or epithelial origin.

A Rare Case of Paediatric Refractory

Hypoglycaemia
IGF- 1 and 2 have structural similarities to insulin, with its action mediated by IGF-1 receptor. IGF-1 and IGF-2 are capable of lowering glucose levels but typically fail to do so because they are normally trapped within the vascular space in a high molecular weight protein complex. IGF-2 induces hypoglycaemia by inhibiting glucose output from the liver and by enhancing glucose uptake by skeletal muscle. In particular, the activation of insulin receptors by IGF-2 promotes continued glucose utilization mainly by the skeletal muscle and suppression of free fatty acid release by adipocytes. This also leads to inhibition of glucose release, glycogenolysis, gluconeogenesis, and ketogenesis in the liver. Furthermore, the release of the counter-regulatory hormones glucagon and GH is suppressed by IGF-2, which in turn magnifies the vulnerability to hypoglycaemia in NICTH. "Big" IGF binds to insulin receptor and can cause similar actions as insulin [5]. Primary event in NICTH is the overexpression of "Prepro" IGF-2 gene by the tumour. Post-translational modifications could be impaired in tumours due to decreased amount of enzymes essential for this process, thus producing "big" IGF-2 [1]. Tumour-derived "big" IGF-2 forms small binary complexes with IGF-binding proteins (IGFBPs), while larger part remains unbound. These binary forms act on insulin receptors after crossing capillary membrane, in turn inhibiting glycogenolysis, gluconeogenesis, decreased lipolysis, and increased peripheral glucose utilization. The supporting laboratory results are low insulin and c-peptide level at the time of hypoglycaemia, low levels of beta hydroxybutyrate, and hypokalaemia.

NICTH should be suspected in all cases of unexplained hypoglycaemia with malignancy. One of the indicators towards the diagnosis of NICTH is low GH. This is especially useful in resource-limited setting where the facility for IGF-2 is not available. "Big" IGF-2 binds to IGFBPs which causes increased free fraction of IGF-1, thus causing negative feedback inhibition of $\mathrm{GH}$.

The immediate aim for the treatment in NICTH is to achieve euglycaemia. Patient can be treated with glucose tablets, glucagon, or intravenous dextrose drips depending on blood sugar values. The final treatment depends on the type of the tumour. Glucocorticoids can be used for immediate acute management of hypoglycaemia. Physiologically, glucocorticoids reduce insulin secretion and increase insulin resistance as well as enhance both gluconeogenesis and glycogenolysis. Dexamethasone and hydrocortisone have been used to treat hypoglycaemia. Surgery is curative if the tumour is resectable. Alternatively, chemotherapy, embolization, or radiation can be used for controlling hypoglycaemia. Steroids are corner-

Dubai Diabetes Endocrinol J 2021;27:162-164 
stone of medical management for NICTH. They decrease the amount of "big" IGF-2 by converting pre-pro IGF into IGF-2, thus normalizing IGF to IGFBP ratio [6].

The patient we have discussed in this case report is one of the first few reported paediatric cases in India of NICTH secondary to rhabdomyosarcoma. A recognized limitation of the case report is that IGF-2 was not measured due to non-availability. However, low plasma levels of IGF-1, insulin, C-peptide, and GH and subsequent CT scan and histology clinched the diagnosis.

\section{Learning Points}

1. NICTH should be suspected in all cases of malignancy irrespective of their age with intractable hypoglycaemia.

2. In the presence of large tumour, hypo-insulinemic hypoglycaemia with low IGF-1, low GH, and low beta hydroxybutyrate, is strong biochemical evidence of $\mathrm{NICTH}$, in a resource-limited setting where in IGF-2 cannot be done.

3. Treatment should be focused at emergency management of hypoglycaemia with resection of tumour whenever possible and prevention of further hypoglycaemia if the tumour cannot be removed.

\section{Statement of Ethics}

The research related to human use complied with all the relevant national regulations, institutional policies, and in accordance to the tenets of the Helsinki Declaration. This case report does not require the approval of Institutional Review Boards in our institute, but a written consent was obtained from the patients' families to participate in the study, to publish the case and the picture of the patient.

\section{Conflict of Interest Statement}

The authors have no conflicts of interest to declare.

\section{Funding Sources}

There were no funding sources for this work.

\section{Author Contributions}

Dr. J.J. drafted the manuscript, revised it critically, and helped in patient management. Dr. N.K. clinically managed the patients and drafted the manuscript. Dr. V.H.N. helped in the management of patient, provided critical intellectual content, and final editing of the manuscript. This manuscript has been read and approved by all the authors and they strongly believe that it represents honest work.

\section{Data Availability Statement}

All data generated or analysed during this study are included in this article. Further enquiries can be directed to the corresponding author.

\section{References}

1 Zapf J, Futo E, Peter M, Froesch ER. Can "big"- insulin-like growth factor II in serum of tumor patients account for the development of extrapancreatic tumor hypoglycemia? J Clin Invest. 1992;90(6):2574-84.

2 Dufresne A, Cassier P, Couraud L, Marec-Bérard P, Meeus P, Alberti L, et al. Desmoplastic small round cell tumour: current management and recent findings. Sarcoma. 2012; 2012:5.
3 Marks V, Teale JD. Tumours producing hypoglycaemia. Diabetes Metab Rev. 1991;7(2): 79-91.

4 Daughaday WH, Emanuele MA, Brooks MH, Barbato AL, Kapadia M, Rotwein P. Synthesis and secretion of insulin-like growth factor II by a leiomyosarcoma with associated hypoglycemia. N Engl J Med. 1988;319:1434-40.
5 Hoekman K, van Doorn J, Gloudemans T, Maassen JA, Schuller AG, Pinedo HM. Hypoglycaemia associated with the production of insulin-like growth factor II and insulin-like growth factor binding protein 6 by a haemangiopericytoma. Clin Endocrinol. 1999;51(2): 247-53.

6 Teale JD, Wark G. The effectiveness of different treatment options for non-islet cell tumour hypoglycaemia. Clin Endocrinol. 2004; 60(4):457-60. 